Estudios sobre armas antiguas, arte militar $\mathrm{y}$ vida cultural en oriente y occidente

XXXVII (2017), pp. 129-151

ISSN: 0436-029X

doi: 10.3989 /gladius.2017.05

\title{
ARTILLERÍA NAVAL VENECIANA EN LA TORRE DEL ORO: MÉTODO PARA LA IDENTIFICACIÓN Y ANÁLISIS DE UN MOSCHETTO DA BRAGA DEL SIGLO XVI*
}

\author{
VENETIAN NAVAL ARTILLERY IN GOLD TOWER (SPAIN): \\ METHOD FOR IDENTIFICATION AND ANALYSIS OF \\ A MOSCHETTO DA BRAGA IN XVI CENTURY
}

\author{
POR \\ Juan José SÁnchez-BaenA ${ }^{* *}$ y Pedro Fondevila-Silva ${ }^{* * *}$
}

\section{RESUMEN - ABstract}

En el Museo Naval de la Torre del Oro de Sevilla se ha localizado una pieza de artillería naval de retrocarga, similar a un cañón, que está erróneamente identificada y sin estudiar. Es un esmeril de braga o moschetto da braga probablemente de origen veneciano del siglo XVI, del cual no conocemos ningún otro ejemplar en los museos españoles. Ha estado sumergida en el mar mucho tiempo. Se realiza un estudio histórico de la artillería de la época, así como la descripción y análisis pormenorizado de este objeto único en España. Ante la falta de bibliografía específica, se ofrecen un método de medición y otro de pesado, basados en textos de la época. El análisis de la documentación histórica permite conocer cómo era el sistema para fundir las pelotas de esmeril, hechas de plomo y hierro, hasta ahora inédito, y establecer su densidad.

The Naval Museum of Torre del Oro in Seville we have located an naval artillery piece similar to a gun that is not described and misidentified breech. This cannon is a moschetto de braga, gives Venetian sixteenth century, which we know of no other copy in Spanish museums. This part has been under the sea for a long time and possibly was rescued by chance and delivered to the museum for preservation. With a view to identification, a historical study of the artillery of the time and description and detailed analysis of this unique object is performed in Spain. In the absence of specific literature on these weapons, we offered a measurement method and other heavy, based on the historic texts. The analysis of historical documentation allows know how the system was to fuse the grinding balls made of lead and iron, hitherto unpublished, and establish its density.

\section{Palabras Clave - Keywords}

Esmeril de braga; galera; galeaza; siglo XVI; Mediterráneo; retrocarga; másculo; Venecia; Artillería naval.

Esmeril de braga; Galley; XVI Century; breechloader; Mediterranean sea; Venecia; Naval Artillery; Naval Ordnance.

* Este trabajo es uno de los resultados de proyecto NAUTICUM, con referencia 19496/PI/2014, financiado por la Fundación Séneca (Agencia de Ciencia y Tecnología de la Región de Murcia).

** Cátedra de Historia y Patrimonio Naval, Universidad de Murcia, baena@um.es / ORCID iD: http://orcid.org/00000002-5965-9016.

${ }^{* * *}$ Cátedra de Historia y Patrimonio Naval, Universidad de Murcia, cazalamesana@gmail.com / ORCID iD: http:// orcid.org/0000-0002-0439-8410. 


\section{Cómo citar eSte ARTículo / CitATion}

Sánchez-Baena, J. J. y Fondevila-Silva, P. (2017): «Artillería naval veneciana en la Torre del Oro: método para la identificación y análisis de un moschetto da braga del siglo XVI». Gladius, XXXVII: 129-151. doi: 10.3989/ gladius.2017.05

\section{INTRODUCCIÓN}

El objetivo principal de este trabajo es analizar una pieza de artillería naval hasta ahora desconocida. Debido a la falta de bibliografía al respecto, también describimos su uso y, sobre todo, proponemos una metodología que pueda ser utilizada para la identificación, pesado y determinación del calibre de este tipo de artillería. Durante el proceso de investigación se ha descubierto nueva documentación sobre el sistema de fundición de las pelotas de esmeril, fabricadas de plomo y hierro, lo que nos ha permitido averiguar la densidad de la pelota y establecer un método para determinar su calibre y el viento de la pieza.

En el siglo XVI Venecia seguía estando en la cima de su poder como potencia marítima y comercial. Una de las claves de su éxito, al igual que la Sublime Puerta, radicaba en la creación de arsenales, es decir, lugares contiguos al mar donde se fabricaban, reparaban y conservaban las embarcaciones de guerra, y donde también se almacenaban los materiales de construcción, los pertrechos y armamentos de dichos bajeles. La Serenísima encargaba a fundidores venecianos, la fabricación de artillería para dotar a sus galeras y galeones, y para contar con reservas en su Arsenal. Esta artillería "estatal" está bastante documentada y estudiada (Santarini, 2011). Sin embargo, no sucede lo mismo con otros fabricantes venecianos que manufacturaban piezas para buques mercantes y para la exportación ${ }^{1}$, de los cuales la documentación identificada y los estudios hasta ahora realizados son escasos.

\section{ESTADO DE LA CUESTIÓN}

Sobre artillería hay variadas obras, tanto inéditas como publicadas, desde los inicios de la Edad Moderna, aunque hay que tener en cuenta que el concepto en sí ha variado a lo largo de los siglos, restringiéndose progresivamente hasta la actualidad. En el artículo que realizamos sobre el esmeril bastardo "matacapitanes" (Fondevila y Sánchez-Baena, 2012) ya pusimos de relieve el estado de la cuestión sobre algunos de los más importantes trabajos pasados y presentes referidos a la artillería en la Edad Moderna en general y al siglo XVI en particular.

Un fenómeno común a todas las obras del siglo XVI es que solamente tratan de la artillería terrestre, con escasa mención al uso naval. De hecho, la diferencia esencial en esa centuria entre ambas está en los encabalgamientos, cureñas, cajas, cepos, carretones, ciriales, tragantes y un largo etc. de modelos para asentar las piezas sobre unas cubiertas oscilantes. De esta materia apenas hay en la documentación de la época una breve mención del nombre sin más explicación. Hay que esperar al siglo XVII para que aparezcan algunos dibujos de cureñas navales y reglas para construirlas.

Es importante diferenciar entre los tratados escritos por expertos en la práctica artillera y los que han sido desarrollados documentándose, pero sin dominio profesional de esta materia. Los primeros son de gran ayuda para identificar, medir y pesar, mientras que los otros, sin

1 Archivo General de Simancas. Guerra Antigua. Secc. Mar y Tierra, Leg. 206 y 214. 
menospreciar su relevancia, suelen desorientar, especialmente cuando se buscan tipos o datos concretos que permitan identificar objetos hallados.

El Tratado de Artillería del Capitan Gaspar Gonzalez de San Millan, Artillero Mayor de la Casa de Contratacion de las Indias, de la Ciudad de Sevilla, redactado hacia mediados del siglo XVI, trata sobre la artillería naval y está escrito por un profesional (Fernández Duro, 1996, VI: 481-500).

En el segundo tipo estarían Diego de Álava (1590), que explica en su obra lo que significan una parte de estas armas, aunque con errores apreciables, fruto, posiblemente, de la falta de dominio del arte. Lo mismo ocurre con la obra de Diego Ufano (1613) que si bien conoce la artillería en uso en Flandes, introduce datos de la construida en otros países a partir de informaciones indirectas.

El tema también es tratado en algunas obras de construcción naval (García de Palacio, 1587) y de navegación (Escalante, 1575) donde se encuentran capítulos y apartados sobre artillería naval que, si bien están dedicados a la organización y al combate, no dejan de presentar información interesante sobre los modelos de bocas de fuego. También varios manuscritos, entre ellos el de Andrés de Espinosa, recogido por Fernández Duro (1996, Vol. VI: 440-456), que junto al de Gaspar González de San Millán (Fernández Duro, 1996, Vol. VI: 480-500), proporcionan importantes datos acerca de la artillería naval y su diferencia con la terrestre.

Entre las obras escritas en otros países merece mencionarse la de Capo Bianco (1598), el capitán de Cremona, y la de Alberghetti (1699), de la importante familia de fundidores de la República de Venecia, que se publicó tras su muerte. También la del capitán portugués Marcos Cerveira de Aguilar (1640-41), con interesantes detalles acerca del combate naval.

En cuanto a los autores como Collado (1592), Rojas (1598) y Firrufino (1626), hay que decir que sus trabajos están orientados a la artillería terrestre, aunque este último tiene algunos párrafos sobre artillería naval. Avanzando en el tiempo, pero en la misma línea podemos incluir importantes tratados sobre la materia como por ejemplo Ríos (1767) o Salas (1831). Ya en la época contemporánea hay varios autores, entre los que destacamos a Vigón (1947) y a Vicente Maroto (2002-2003).

Más en concreto, Morin (2002, 2009 y 2011) en sus diversas publicaciones se ha ocupado de las armas, fundiciones y técnicas usadas en la República de Venecia en el siglo XVI. Avery (2003) estudió detenidamente el papel de dos de las fundiciones más importantes, propiedad de los Conti y los Alberguetti.

Ashtor (1981) analiza la artillería naval como un punto fuerte del poder veneciano. También Santarini (2011) la ha estudiado, concretamente una culebrina de 50. Por otra parte, Scordato (2011) analiza dos piezas navales venecianas extraídas en el estrecho de Mesina, de fines del siglo XVI, y propone una forma de estimar el peso de las piezas, cuestión que trataremos más adelante.

El artículo publicado por Fondevila y Sánchez Baena (2012), se centra en un esmeril de la segunda mitad del siglo XVI, procedente de una fundición española, que actualmente se halla en el Palacio-Museo del Viso del Marqués. El diseño de esta pieza supuso un notable avance en los esmeriles de la época, especialmente para los utilizados en las galeras. Por otro lado, se descubrió el uso de la rabiza portátil, con un sistema parecido que hasta ahora no había sido interpretado, lo que abre nuevas perspectivas de análisis para este tipo de piezas.

Ridella et al. (2016), en un trabajo impecablemente presentado, sacan a la luz varias piezas de indudable valor arqueológico e histórico. Es la publicación más reciente sobre esta materia, y se ocupa de varias bocas de fuego de bronce halladas en la costa de Israel. Son dos sacres y un falconete venecianos de fines del siglo XVI, procedentes de un naufragio sucedido cerca de Haifa. 


\section{TIPOLOGÍA DE LA ARTILLERÍA NAVAL DEL SIGLO XVI}

Las piezas de artillería naval de la época estaban divididas en tres géneros: las culebrinas, los cañones y los pedreros. A su vez, cada género tenía un abundante número de modelos que iban variando según el criterio del fundidor o el resultado que hubieren dado. ${ }^{2}$ Dependiendo del objetivo al que iban dirigidas, había un conjunto de piezas cuyo propósito principal era ofender (atacar) el buco, árboles y aparejos de la embarcación enemiga, que denominaremos, para hacer una distinción clara, "antibuque"; y otro grupo encaminadas a batir a la dotación enemiga, las cuales llamaremos "antidotación".

Así, el objeto que nos ocupa está dentro de las armas "antidotación" que estaban formadas por las piezas menores del tipo culebrina, normalmente por esmeriles y por diferentes tipos de pedreros: cañones pedreros, busacos y morteretes. Los esmeriles servían para tirar contra blancos determinados. Los cañones pedreros y busacos, lanzaban balas o bolardos de piedra caliza, los cuales, al chocar con un cuerpo sólido, se disgregaban en numerosas esquirlas que actuaban a manera de metralla contra la dotación. Los morteretes, que también podían lanzar balas de piedra, se utilizaban para disparar lanternas, que eran unos cilindros huecos de madera blanda, rellenas de perdigones, dados de hierro o lascas de pedernal, que funcionaban como botes de metralla.

Dependiendo de cómo se cargaban, según Morin (2002), se puede establecer la siguiente tipología para el espacio temporal correspondiente a este trabajo:

a) Artillería de avancarga. Es la que se cargaba por la boca de la pieza. Primeramente se introducía el saquete de pólvora, a continuación un taco de filásticas, luego la pelota o bala y, finalmente, otro taco de filástica, que impedía que la bala se moviese dentro del ánima de la pieza de artillería. Comprendían este grupo (Morin, 2002: 19-21):

— Esmeril o moschetto de 1 libra, ${ }^{3}$ calibre ${ }^{4}$ de cerca de $45 \mathrm{~mm}$ y longitud en torno al metro.

— Esmeril de prácticas o moschetto da zuogo de 1 libra, calibre cerca de 42/45 mm y longitud entre $140 / 160 \mathrm{~cm}$.

- Falconete o falconetto de 3 libras, calibre entre 50/55 $\mathrm{mm}$ y longitud oscilando entre $140 / 160 \mathrm{~cm}$.

— Falcón o falcone de 6 libras, calibre $62 / 65 \mathrm{~mm}$ y longitud entre 170/180 cm.

— Áspid o aspide de 12 libras, calibre 95/100 mm, longitud 170/180 mm.

- Sacre o sacro de 12 libras, calibre 95/100 mm, longitud 210/270 mm También hay noticia de un sacre de 14 libras, pero Morin lo hace equivalente a la culebrina de 14 libras.

- Culebrina o colubrina de 14, 20, 30, 40, 50, 60, 90, 100, 120 libras.

- Cañón o cannone de 16, 20, 30, 40, 50, 60, 90, 100, 120 libras.

b) Artillería de retrocarga. También llamada de "cámara abierta". En este tipo de piezas se cargaba la pólvora, exclusivamente, por la parte trasera del ánima que estaba abierta. La pólvora iba dentro de un depósito metálico, el másculo, que cerraba el ánima. El resto de la carga se efectuaba como en las piezas de avancarga, excepto que se suprimía el primer

2 Biblioteca Nacional de Portugal. Serneira de Aguilar, M. Ms. "Advertencias de Navegantes". Primera mitad del siglo XVII. Cod - 13390, fol. 18 v.

3 Las libras son venecianas. En relación al asunto de si son libbre peso grosso o libbre peso sottile véase el apartado 4, dedicado al estudio detallado de la pieza.

4 Aquí Morin emplea la voz calibre en el sentido moderno de diámetro del ánima. 
taco de filástica, dado que el de madera del másculo, que cerraba el depósito, hacia el papel de éste. Estaban formadas por (Morin, 2002: 19-21):

- Esmeril de braga o moschetto da braga de 1 libra, calibre $45 \mathrm{~mm}$, longitud 1m. (Fig. 1).

- Pedrero de másculo o petriera da mascolo de 6 libras, 6 libras, calibre $70 \mathrm{~mm}$, longitud sin codetta alrededor de $1 \mathrm{~m}$.

- Pedrero de braga o petriera da braga de 12 libras, calibre $95 \mathrm{~mm}$., longitud en torno a $130 \mathrm{~mm}$.

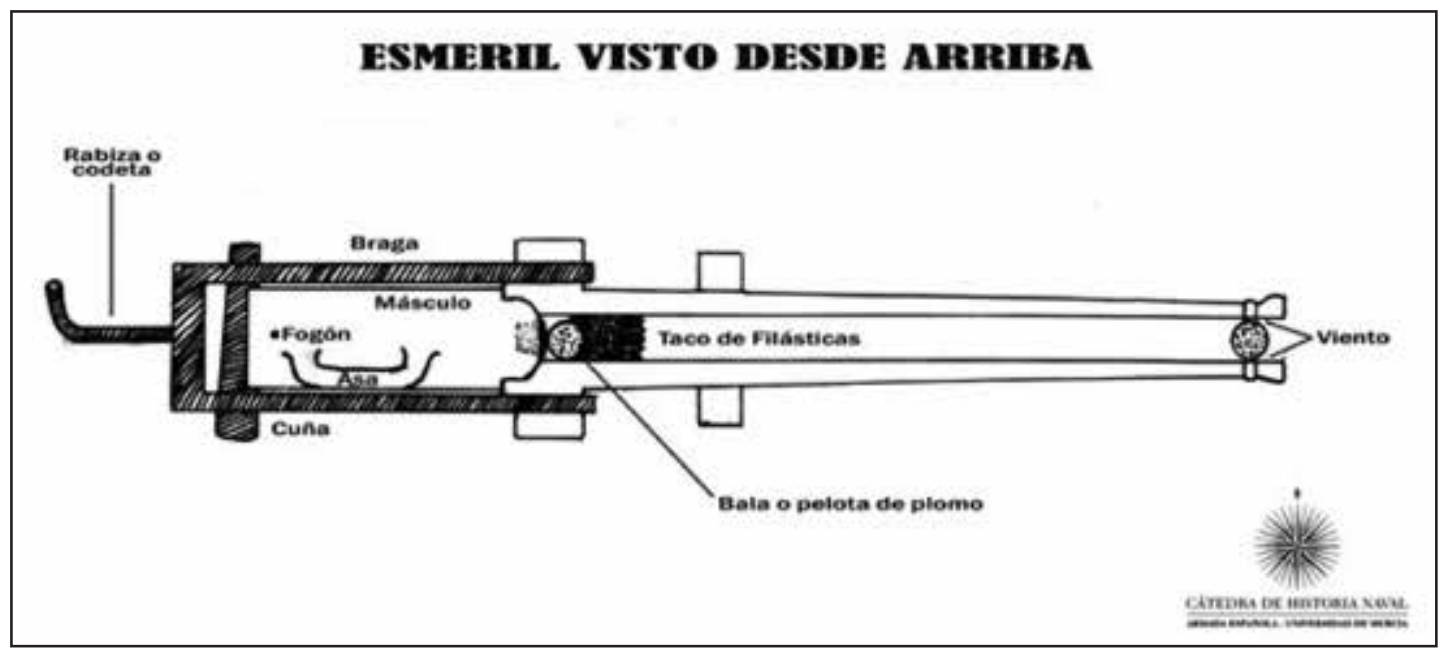

Figura 1. Dibujo del esmeril visto desde la parte superior.

\subsection{Algunos aspectos Para identificAR la artillería naVAl Del Siglo XVI.}

Antes de entrar en el estudio de la pieza, nos parece necesario establecer una base de partida sobre algunos aspectos de la artillería naval del siglo XVI, especialmente porque son los que van a determinar el origen, datación y uso del arma objeto de análisis.

a) Bronce versus hierro para la fabricación de las piezas de artillería.

Profundizando en el interés de la pieza objeto de este estudio en particular, y en la insuficiencia de ejemplares existentes en los museos españoles de artillería naval de bronce de los siglos XVI al XVIII en general, hay que decir que la escasez fue consecuencia de la reutilización de los cañones estropeados, desfogonados, o anticuados, que se fundían para hacer nuevas piezas. ${ }^{5}$

Relacion de lo que pesaron las nueve Moyanas de Bronze que últimamente desecharon las Galeras de Spaña y se entregaron a henrique bauet Asentista de la fundicion de la Artilleria de esta ciudad por estar inútiles y para que fuesen a fundir y fabricar otras nueve Moyanas. ${ }^{6}$

\footnotetext{
5 Archivo Museo Naval de Madrid. Colección Sanz de Barutell, art. 6 núm. 20.

6 Archivo Museo Naval de Madrid. Colección Vargas Ponce, tomo XXVII, doc. 39.
} 
Esta práctica venía motivada por el alto precio de los cañones de bronce en comparación con los del mismo tamaño realizados en hierro colado. La proporción, variable según la época, estaba en un valor de 8 a 10 veces más cara la pieza de bronce que la de hierro. Según Guilmartin (2002), el precio del bronce en Inglaterra era de $31 / 3$ a 6 veces más caro que el hierro, relación que alcanzó el de $81 / 3$ en 1670. Este valor tan alto del bronce, hacia que la mayoría de las piezas fuesen pesadas y su resultado marcado en la fundición, y que éste figurase en los inventarios y listas de la artillería.

Fecha 8 de Mayo de 1587, Napoles. Cargo de armas y artilleria y otras cosas pertenecientes a ella: Un cañon de bronze de 12 palmos largo, de 50 libras de bala, con armas reales y del Marques de Mondejar con letrero Opus Christoforo de jordano, de Napoles A.D. 1579, de peso señalado a la culata, quintales 34 , rotulos 36 , con su caxa y ruedas husadas herradas. ${ }^{7}$

Por otro lado, la seguridad que ofrecía el bronce ante el hierro en el caso de que el cañón reventase (las piezas de bronce solamente se abrían o rajaban mientras que las de hierro se rompían en múltiples trozos que volaban como metralla), era un factor decisivo a la hora de decidir el material de las piezas de artillería, que de forma casi exclusiva eran de bronce, en las galeras o en las embarcaciones de guerra, quedando el hierro, sin excluir el bronce, para las mercantes. En este sentido, es de destacar la solución dada para abaratar el esmeril de braga, manteniendo el bronce en la caña y másculo, mientras que se empleaba el hierro en las partes restantes. Veamos un ejemplo, en un trabajo de la época:

Toda la artillería se suele hacer de uno de dos géneros de metales; que uno es bronce y el otro hierro. (...) Más, está experimentado que, toda la artillería de hierro de cualquier suerte que sea, sacando los arcabuces, versos y mosquetes, es mala y perjudicial, y podía decir que en las naos, y en el mar no sirve sino de embarazar; y así, suelen decir los navegantes que de ella tiene noticia, que la artillería de hierro mata a la gente de dentro, y espanta a los de afuera, y el mejor metal que hasta ahora se ha hallado para piezas grandes de artillería es el buen cobre, mezclado con buen estaño que sea blando y limpio de otros metales (Escalante, 1575: 44).

Con respecto a las galeras, el bronce presentaba una ventaja adicional, pues, para piezas del mismo tipo y calibre, éstas tenían alrededor de un 10\% menos de peso que las de hierro. La diferencia tenía su importancia en el caso de las bocas de fuego principales situadas en la corulla, especialmente en el cañón de crujía que era la más pesada, por el riesgo de quebranto, en caso de mal tiempo, de la estructura longitudinal del buco de la galera, que tenía una alta relación eslora/manga, al límite de las posibilidades de la construcción naval de la época (Boudriot, 1992: 26).

\section{b) La forma de medir el peso de los cañones.}

En primer lugar hay que determinar en qué medidas se ha expresado el valor del peso de la pieza. En la documentación española se registra cuando figura grabado el país al cual corresponden las medidas. Cuando no aparece grabado se hace una estimación del mismo, dado que en las escuadras y flotas carecían de las grandes romanas que las fundiciones utilizaban para medir las piezas (Fig. 2). En este caso el valor se entiende que es en medidas españolas.

7 Archivo General de Simancas, Guerra Antigua, Secc. Mar y Tierra, leg. 214-46. 


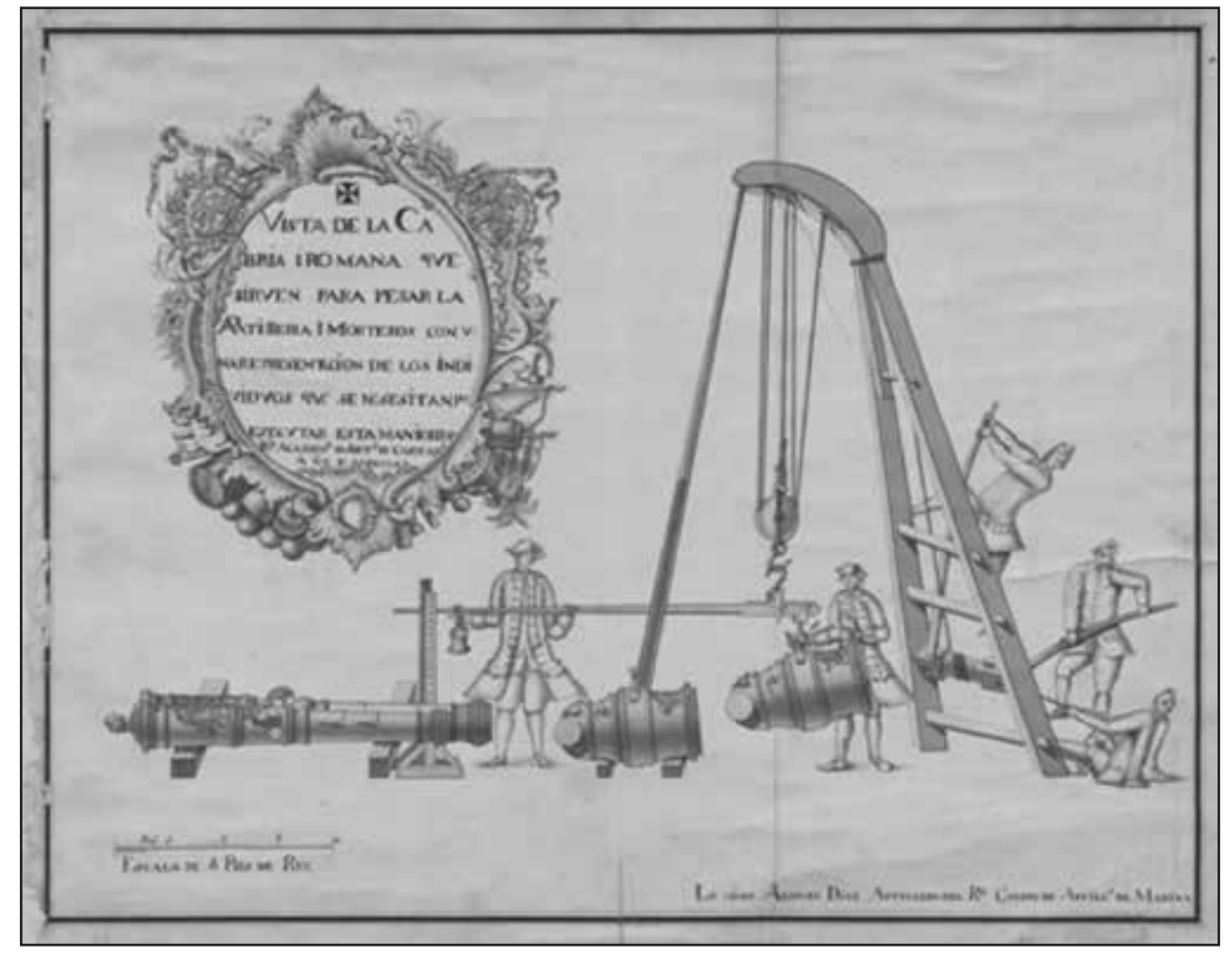

Figura 2. Representación del pesaje de piezas de bronce. Aparecen la cabria o cabrilla y la gran romana. Aunque el dibujo data de 1770 , los aparatos utilizados en la medición son iguales a los del siglo XVI. Fuente: Archivo Museo Naval de Madrid, Colección Dibujos Técnicos, Sig. MNM PB 0205 .

En segundo lugar hay que considerar que el peso corresponde exclusivamente a la pieza, y no contempla el de másculos, horquillas o forquetas, calces o cuñas, bragas o rabizas. Cuestión ésta que no hay que olvidar en las piezas recuperadas con braga u horquilla.

Dos sacres fundición de Napoles de pesso de uno, ocho quintales y treinta y ocho rotulos pesos de alli; y el otro de peso ocho quintales y cincuenta y seis rotulos. ${ }^{8}$

Quatro esmeriles el uno pesa tres quintales y cincuenta libras peso de Castilla... ${ }^{9}$

Quatro esmeriles de diferente fundicion que pesaran a quintal cada uno tiran a seis y a ocho onzas de vala de plomo. ${ }^{10}$

En este sentido, conviene traer a colación que en esa época existía en Málaga una famosa fundición de artillería dirigida por Francés de Álava (Vicente Maroto, 2002-2003), en la cual disponían de la cabria o cabrilla y de la gran romana, necesarias para pesar la artillería. Un documento del Archivo de Simancas recoge una relación de piezas de artillería véneta procedentes de un naufragio que tuvo lugar en 1586 en el Estrecho de Gibraltar, que posteriormente

\footnotetext{
8 Archivo Museo Naval de Madrid. Colección Sanz de Barutell, art. 4, núm. 1070.

9 Ibídem.

10 Ibídem.
} 
la Corona española compró y tras ello ordenó pesar en la ciudad de Málaga. ${ }^{11}$ El hecho de que se pesase la artillería parece indicar que las piezas venecianas, al menos las más sencillas y sin ningún adorno, no llevaban grabado el peso, o bien que lo llevasen en peso veneciano y, habiendo dificultades para fijar el escandallo (la equivalencia de medidas), se pesaron para establecer el precio, que parece que se calculó para quintales castellanos. La posible discrepancia puede ser debida a dos razones diferentes:

1) A que el cargamento de la embarcación veneciana fuese de fundidor no "estatal", es decir que sus modelos no se ajustasen a los tipos determinados por la Serenísima, que no llevasen grabado el peso y que, además, como parece probable, los fabricantes fuesen varios.

2) A que en España se entendía por sacre el cuarto de culebrina. Ésto quería decir que el peso en libras de la bala que lanzaba el sacre pesaba, dentro de unos límites "elásticos", la cuarta parte de la bala que lanzaba la culebrina ordinaria. Aunque este concepto era compartido por todos los estados marítimos mediterráneos, no ocurría lo mismo en relación a las características de la culebrina ordinaria, que variaban incluso dentro del mismo reino.

c) Cambio en la forma de cargar la pólvora: del sistema de cuchara al de ensacado.

Según la forma de cargar la pólvora había tres tipos de piezas:

- De "cámara abierta" o de retrocarga ya nombradas, en las cuales la parte posterior del ánima, la cámara o recámara donde se aloja el cartucho de pólvora, está abierta por arriba para permitir la introducción de un másculo, cámara, recámara, servidor o alcuza, que era un depósito de metal, provisto de fogón, relleno de pólvora, que se acoplaba y trincaba al final del ánima. Modelo muy corriente en España.

- De braga, lo mismo que de "cámara completamente abierta", en él la caña del esmeril acababa en un hueco para acoplar el másculo, el cual se ligaba a la caña por medio de una braga de hierro en forma de U, hecha firme a las "orejas" que tenía en el zuncho o faja con que acaba la caña. Este modelo era común en Venecia y otras partes de Italia.

- De "cámara cerrada", el modelo empleado en las piezas de mayor calibre de los géneros cañón, culebrina y pedrero.

En esta centuria se empezó a cargar la pólvora en saquetes a bordo de los buques: "Este modo de cargar las pieças con cartuchos fue inventado, $y$ debe usarse en bajeles" (Firrufino, 1626). Esta decisión vino motivada por las dificultades y riesgos que entrañaba el cargarla con cuchara en una plataforma oscilante como es una embarcación. En las piezas de pequeño calibre se siguió usando el primitivo sistema de las bombardas, el servidor, cámara o másculo, que, relleno de pólvora, se acoplaba al final del ánima (Fig. 3).

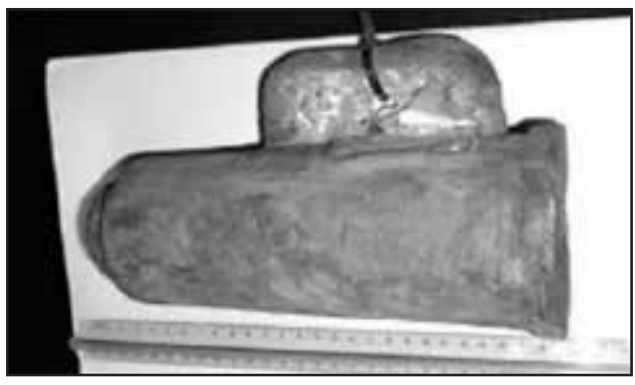

Figura 3. Un másculo de bronce con su gruesa asa. Fuente: Morin, 2011.

11 Relacion de la artilleria que se ha comprado por horden del Rey nuestro señor, de Marco Antonio Valeñan, capitan de la nave veneciana que dio al traves en la punta del Carnero (entrada a la bahía de Algeciras en el Estrecho de Gibraltar) por octubre de mil y quinientos y ochenta y seis, y lo que pesa peso de Castilla segun la ha pesado Hernando Alonso vezino de la ciudad de Malaga con el peso del artilleria de ella. Archivo General de Simancas, Guerra Antigua, Secc. Mar y Tierra, Leg. 214-62. 
Este procedimiento, además de evitar los riegos de cargar con la pólvora sin ensacar, tenía la ventaja de que, teniendo dos o tres másculos por pieza, se aceleraba la recarga, dado que un hombre cargaba el másculo mientras otro introducía por la boca la pelota y el taco (Fig. 4), "mas quarenta masculos de bronze para servicio de los dichos veynte esmeriles". ${ }^{12}$

\subsection{La ARTILLERÍA NAVAL VENECIANA DEL SIGLO XVI.}

La República de Venecia había alcanzado su apogeo económico y político a mediados del siglo XV. En esas fechas había ampliado su expansión terrestre por los territorios del Véneto y de la Lombardía y poseía una flota de más de 3.000 embarcaciones. Sus líneas comerciales abarcaban toda la parte oriental del Mediterráneo, incluyendo el Mar Negro y el Mar de Azov, y se prolongaban por el Mediterráneo occidental hasta llegar incluso a Inglaterra y Flandes.

A partir de la toma de Constantinopla por los turcos en 1453 comenzaron los problemas económicos y políticos. El descubrimiento de América por España

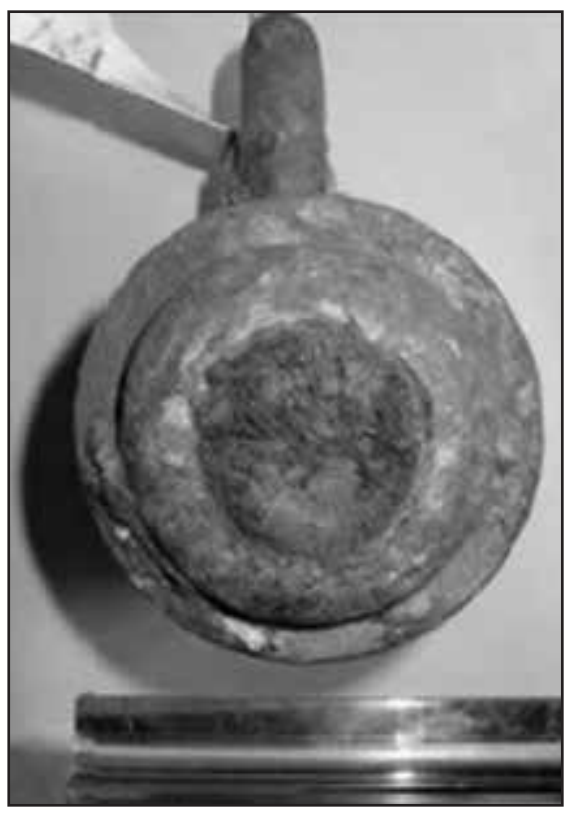

Figura 4. Vista delantera del másculo. Se aprecia el taco de madera blanda que cerraba la carga de pólvora. Fuente: Morin, 2011. y la expansión portuguesa por la costa africana hasta llegar al Maluco, desviaron las grandes rutas comerciales del Mediterráneo al Atlántico. Al mismo tiempo, Venecia se vio obligada a sostener una lucha militar y política con el Imperio Otomano, que siguiendo su expansionismo terrestre había alcanzado las costas del Adriático en 1480, amenazando los enclaves venecianos en ella situados.

A comienzos del siglo XVI, la República Serenísima seguía siendo muy poderosa, Venecia era la segunda urbe de Europa, solo superada por París, y una de las más ricas del mundo. Destacaba por encima del resto de los estados de la península italiana, interviniendo en los conflictos internacionales merced a su poderío territorial y marítimo. Pero la acción de la Liga de Cambray en 1518, puso freno a la expansión veneciana por el norte de Italia. Como consecuencia de ello, tuvo que volcarse más en mantener y acrecentar su poder naval, tanto mercante como militar (Ashtor, 1981).

Una de las soluciones adoptadas fue intensificar la producción de artillería naval, tanto para las embarcaciones de guerra como para las mercantes, armadas por particulares. Este tipo de artillería se fabricaba, prácticamente en su totalidad, en bronce (Morin, 2009). El impulso dado a las fundiciones que trabajaban para el Estado, propició el nacimiento de dinastías de fundidores como los Alberghetti y los di Conti (Avery, 2003), cuyos talleres fueron dominantes durante este siglo, fabricando no solo para la Serenísima, sino, también, para dotar a las embarcaciones particulares; actividad ésta y la de exportación en las que participaron otros obradores más modestos y menos conocidos.

Para el propósito de este trabajo es pertinente indicar que la catalogación de las piezas estatales es relativamente sencilla (Morin, 2009), dado que éstas llevaban el león de San Marcos

12 Archivo General de Simancas, Guerra Antigua, Secc. Mar y Tierra, leg. 214-46, fechado en Nápoles, a 8 de mayo de 1587 
y la marca del Consiglio dei Dieci o Consiglio dei X (antes de finales de 1588) en forma de una $\mathrm{X}$ en relieve, y la inicial del nombre y apellido del fundidor, con la fecha de la fundición. También hacían constar el peso de la pieza en libbre grosse alla veneziana grabada en la faja de la lámpara o culata. En las piezas de cámara abierta, como el moschetto da 1 da braga, el másculo también iba marcado con la efigie del león y el peso.

Cuando se trata de piezas para particulares o para la exportación, sobre todo en las de pequeño calibre, la catalogación se complica, pues aquéllas no llevaban las marcas citadas anteriormente; solamente, y ocasionalmente, las siglas del fabricante. Por ello hay que recurrir, como acertadamente apunta Morin (2009), al análisis de la morfología general de la pieza para su identificación y clasificación (Fig. 5).

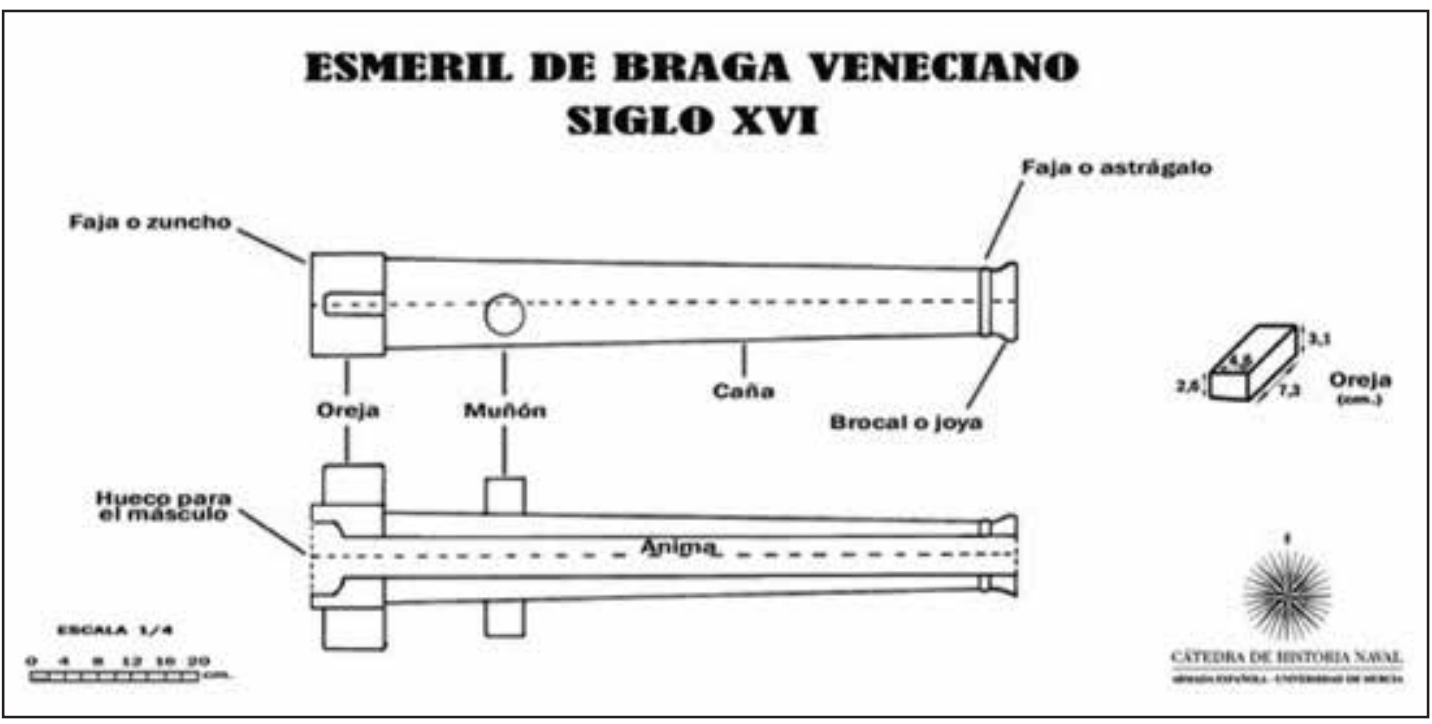

Figura 5. Dibujo de un esmeril de braga veneciano y de sus piezas más significativas.

\section{EL MOSCHETTO DA BRAGA DE LA TORRE DEL ORO.}

\subsection{CARACTERÍSTICAS Y DESCRIPCIÓN INICIAL.}

La pieza de artillería referida (Fig. 6) se halla en el Museo Naval de la Torre del Oro de Sevilla, inventariada con el número 358 e identificada como "cañón de costa/bronce/fundido/ calibre $45 \mathrm{~mm} /$ siglo XVII". No se conoce cuándo ingresó, ni su procedencia.

La pieza en cuestión es la caña de un tipo de artillería muy usado en la mar, el esmeril, moschetto en veneciano, pero que, en este caso corresponde a un esmeril de braga. Empezando por atrás, la caña comienza por un grueso zuncho o faja, de forma cilíndrica, el cual tiene a cada lado una fuerte "oreja" situadas en el eje del ánima. A partir de aquí, la caña toma forma troncocónica, disminuyendo hacia el brocal o joya. Aproximadamente a 1/4 de la parte trasera, están los muñones cuyo centro está por debajo del eje del ánima. La caña acaba con una pequeña faja, el astrágalo, seguida del brocal de la boca de la pieza. 


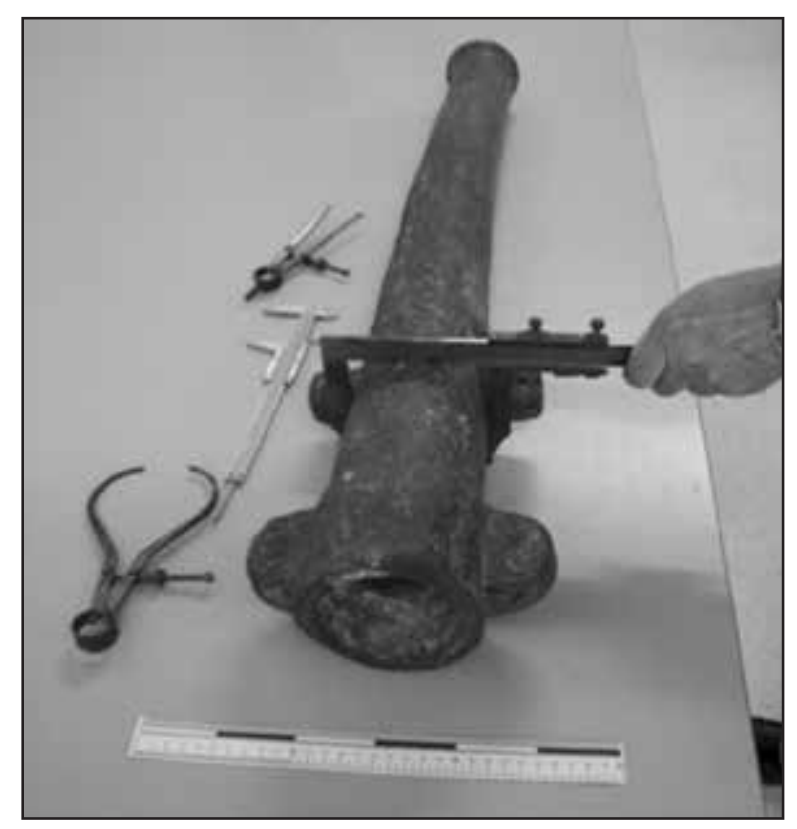

Figura 6. La caña del esmeril de braga analizado durante el proceso de medición. Se aprecia la torsión de la parte delantera.

Tabla 1. Características principales de la pieza.

\begin{tabular}{|l|l|}
\hline Material & $\begin{array}{l}\text { Bronce fundido. Tiene abundantes concreciones de óxido de hierro, sobre } \\
\text { todo en la parte trasera. }\end{array}$ \\
\hline Peso & $37,8 \mathrm{~kg}$ \\
\hline Longitud de la pieza & $84,5 \mathrm{~cm}$ \\
\hline Longitud del ánima & $80,8 \mathrm{~cm}$ \\
\hline Calibre del ánima & $\begin{array}{l}\text { En la boca o joya } 46 \mathrm{~mm} \text {. de diámetro; en la parte trasera } 47 \mathrm{~mm} \text { (Fig. } \\
\text { 7). Toda el ánima está recubierta de una fina capa caliza, de mayor grosor } \\
\text { en la boca de la pieza que, además, está ligeramente deformada. Por esta } \\
\text { razón, tomamos como calibre 47 mm., aunque estimamos que, cuando se } \\
\text { haga una limpieza química del ánima, el diámetro aumentará en 1mm. al } \\
\text { menos. }\end{array}$ \\
\hline Observaciones & $\begin{array}{l}\text { El ánima presenta concreciones calcáreas procedentes de vida marina. La } \\
\text { caña del arma tiene una deformación hacia la derecha y hacia abajo pro- } \\
\text { ducida durante su estancia en el fondo del mar. En la faja o zuncho que } \\
\text { refuerza el final de la caña lleva grabado la marca del fabricante. Tiene } \\
\text { dos muñones colocados por debajo del eje del ánima. Sobre la caña, cerca } \\
\text { del brocal, hay un relieve de un escudo partido en dos cuarteles, en el } \\
\text { campo del cual no se observan figuras. La pieza está cubierta con abun- } \\
\text { dantes concreciones de óxido de hierro. En la parte derecha de la caña se } \\
\text { observa una zona en la cual han desaparecido las mencionadas concrecio- } \\
\text { nes, probablemente por efecto del roce con algún objeto flexible, véase } \\
\text { que la rozadura se adapta a la caña, que podría ser un cabo grueso. Hay } \\
\text { pequeñas pérdidas de material en una de las orejas, en los muñones y en } \\
\text { el brocal o joya. }\end{array}$ \\
\hline
\end{tabular}


Carece de la braga de hierro, formada por la crosetta o cruz, pieza en forma de U; la codetta o rabiza, también de hierro, de forma acodada que se acoplaba a la anterior; la cuña, cuño o cunnos, obviamente de hierro, que servían para acuñar al másculo, pasando por dos ventanas en la parte trasera de la cruz (Fig. 8). También falta la horquilla, forqueta o forquetas de hierro, que sostenían la pieza por los muñones, y el másculo, cámara, recámara, servidor o alcuza, de bronce. Los siguientes textos avalan lo expuesto anteriormente:

Dos esmerillos chiccos de metal con quatro masculos de peso de dos quintales, con dos codettas, dos forquettas, seys cunnos, y dos cruçes todo de hierro. ${ }^{13}$

En cinquenta y seis guarnimientos de crosettas codettas forquetas y cuños de hierro para los esmeriles (...) a quatro guarnimientos por cada galera. ${ }^{14}$

Sobre el primer texto, digamos que aquí la voz metal significa bronce. En cuanto a las medidas de peso rótolo, rótulo en español, era un patrón muy extendido en Italia, que en Nápoles equivalía a 0,8909972 kg (Guglielmotti, 1889: 22). Por lo que respecta al quintale, era un término matemático y de metrología, pero que no tenía uso práctico en Italia (Guglielmotti, 1889: 21). De todo lo expuesto, deducimos que el peso en quintales de los dos esmeriles chicos y sus cuatro másculos, corresponden al quintal de Castilla, que equivalía a 46,0093 kg. Si un esmeril y sus dos másculos pesaban un quintal de Castilla y la pieza objeto de este estudio, pesa 37,8 $\mathrm{kg}$, que podemos redondear a 38 por las pequeñas pérdidas de metal, resulta un peso estimado para cada másculo de $4 \mathrm{~kg}$, que parece razonable. Por último, del mismo texto se desprende que las piezas de hierro de cada esmeril: braga; forqueta u horquilla y los tres cunnos, cuñas o calces, pesaban $22,72 \mathrm{~kg}$.

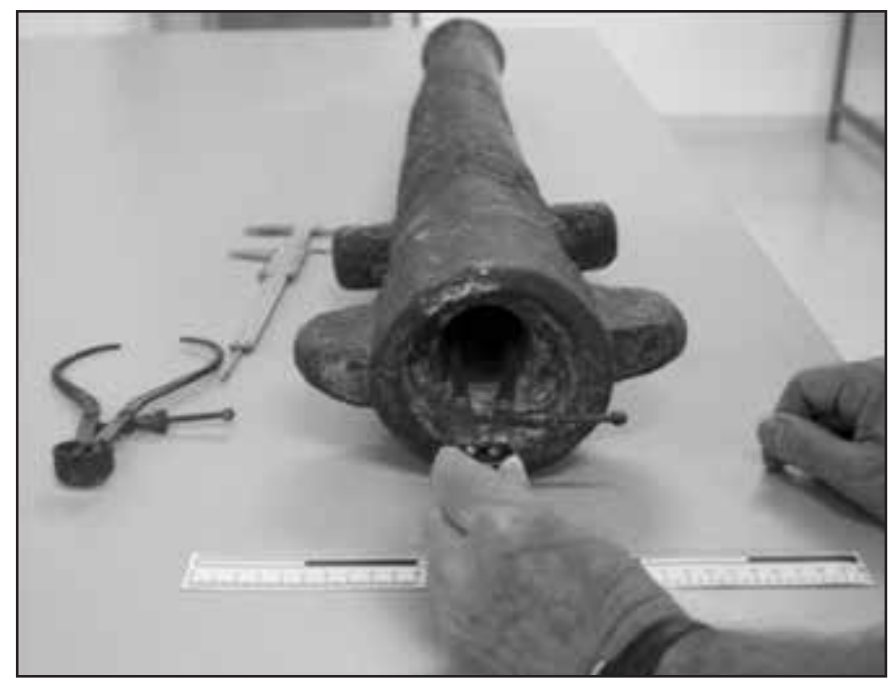

Figura 7. Midiendo el diámetro de la parte trasera del ánima con un compás de interiores. Se observa el hueco para el alojamiento del másculo, las gruesas "orejas" donde se trincaba la braga, los muñones y la curvatura de la boca de la caña.

13 Archivo del Marqués de Santa Cruz. Palacio de Santa Cruz, Madrid. Caja 74. Este quintal sería castellano, equivalente a 46,0093 kg. Si aplicamos este peso al conjunto de una caña más dos másculos, a cada uno de los últimos le corresponderían unos $4 \mathrm{~kg}$. de peso, dato que nos parece coherente.

14 Ibídem, Caja 75. 
Por otro lado, las faltas de la braga, de la forqueta y del másculo, han servido de apoyo para construir la hipótesis sobre el lugar y circunstancias del hallazgo de la pieza.

Los dos esmeriles venecianos que aparecen en la ya citada relación de artillería, ${ }^{15}$ que se compran procedentes de una nave veneciana perdida en el Estrecho en 1586, pesaban cada uno 75 libras castellanas (las cámaras o másculos de todas las piezas se pesaron aparte y conjuntamente), que equivalen a $34,5 \mathrm{~kg}$. Un valor cercano al peso de la pieza en estudio y que, seguramente, variaría según el fabricante.

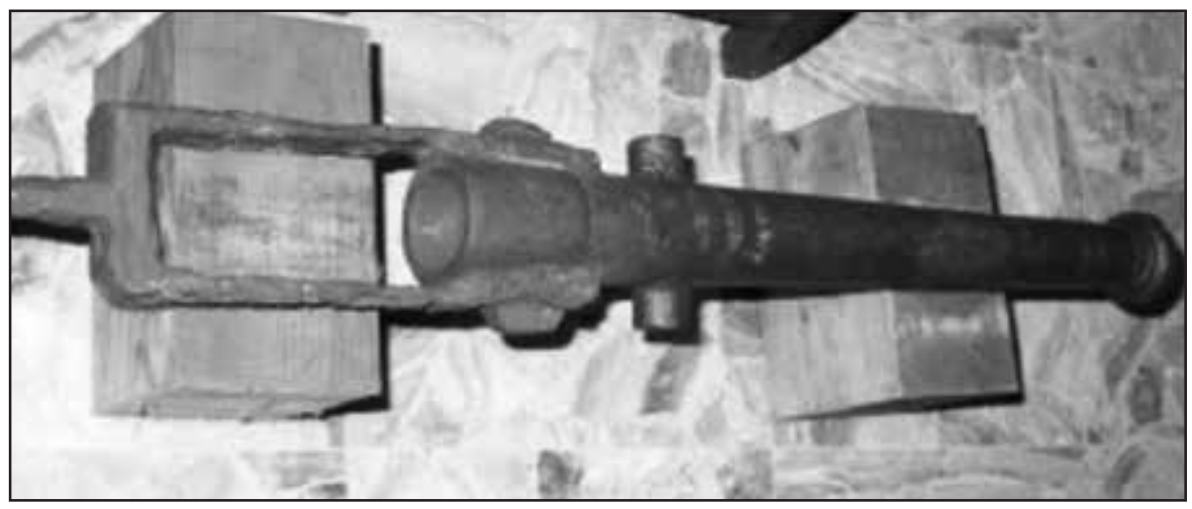

Figura 8. Un esmeril de braga. Se observa la braga de hierro y parte de la rabiza o codetta. Falta el másculo o mascolo. Fuente: Morin, 2002.

\subsection{ORIGEN Y DATACIÓN DE LA PIEZA.}

Ante la falta de datos para evidenciar la procedencia y datar la pieza, hacemos uso tanto de la bibliografía existente como de nuestros conocimientos y experiencia náutica, para ofrecer la información lo más contrastada posible, con el fin de poder llevar a cabo una identificación acertada de esta boca de fuego.

\section{a) Hipótesis sobre el hallazgo}

Tratando ahora del posible origen del esmeril, está claro que éste ha estado durante mucho tiempo en el fondo del mar. Hay que descartar, por tanto, que la pieza procediese de alguna fortificación de la costa. También hay que desechar la hipótesis del hallazgo por un buceador, pues en ese caso es más que posible que también se hubiese recuperado la braga y el másculo, además de no ofrecer explicación para el roce ni para la torsión de la caña del arma (Fig. 9). La teoría que parece más plausible es que la caña del esmeril fuese enganchada por la jareta y relinga baja del copo (saco de red), de un aparejo de pesca de arrastre. Primeramente se produjo el roce y la torcedura de la caña, hasta que se rompió la braga (que era de hierro y estaría más deteriorada por el largo tiempo de estancia en el mar), quedando ésta y el másculo en el fondo, mientras que la caña fue recogida por el copo de arrastre, apareciendo en la cubierta del barco al descargar la pesca. Posteriormente la pieza pudo ser entregada a las autoridades y llegar al Museo.

15 Archivo General de Simancas, Guerra Antigua, Secc. Mar y Tierra, Leg. 214-62 


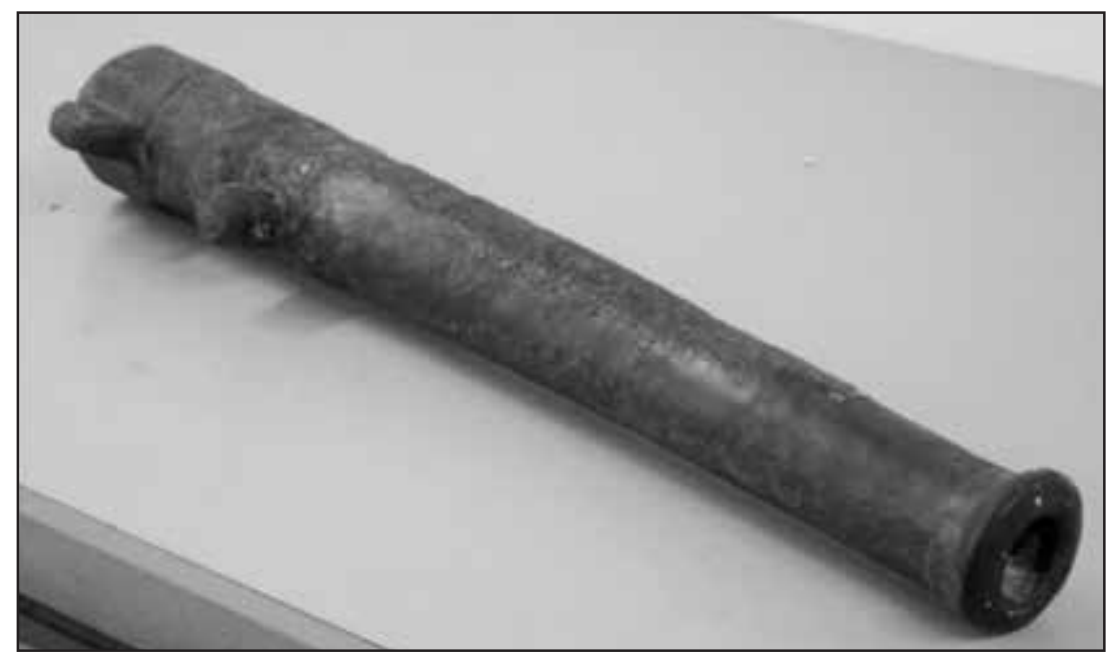

Figura 9. En ella se puede observar la curvatura del comienzo de la caña y las señales de rozadura con un objeto blando y flexible.

b) Hipótesis referida a que el origen de las piezas de artillería es el mismo que el buque que las cargaba

Una vez identificada la pieza, se plantea la nacionalidad del pecio en que se encontraba que, con frecuencia, principalmente en los siglos XVI y XVII, no coincidía con la del país fabricante del arma. En el caso de las galeras (Fondevila, 2010), aunque la casuística es variada, podemos mencionar las siguientes prácticas: al darse de baja una, la nueva que le sustituía "heredaba" la artillería; cuando se apresaba una embarcación enemiga, su artillería se repartía entre las galeras apresadoras; los capitanes generales de las escuadras de galeras solían encargar piezas en otros reinos o dominios de España, o comprarlas a comerciantes extranjeros. Así en un documento ya citado anteriormente, aparecen piezas de artillería veneciana:

Relacion de las piezas de artilleria que ay en todas las galeras de España y de su peso y Calibo que tienen en el puerto de Santa Maria 11 de noviembre de 1590: Galera S. Francisco: Dos medios sacres fundición de Venecia de peso de seis a siete quintales cada uno tiran de vala quatro libras y media; Galera Sta. Barbara: Dos medios sacres fundicion de Venecia pesan a 12 quintales cada uno tiran de vala quatro libras y a tres y media. ${ }^{16}$

Este documento nos permite obtener una completa visión de las prácticas al uso en cuestión de armamentos, pues, a título de ejemplo, en el texto aparece, confirmando lo anteriormente formulado, que las bocas de fuego de esas galeras eran originarias de diez países y reinos diferentes.

En cuanto a las piezas de artillería de bronce sacadas del mar, hay que destacar que es muy frecuente que éstas hayan perdido algún elemento, sobre todo en las recuperadas en fondos poco profundos, en los cuales se hace sentir el efecto de las tempestades. Este fenómeno es más acusado en las piezas de pequeño calibre y de cámara abierta, siendo las carencias más frecuentes la falta del servidor, recámara, másculo o alcuza; la pérdida del asa de este elemento, por golpearla con un martillo, en vez de la maza de madera, para encajar el másculo en la

16 Archivo Museo Naval de Madrid, Colección Sanz de Barutell, art. 4, núm. 1070. 
cámara de la pieza; la desaparición de la rabiza o rabera; el extravío de las cuñas o calces; la carencia del cepo o braga, de la horquilla o del másculo, cuando este era de hierro, por corrosión. Todo lo anterior explica el que se produzcan equivocaciones en la interpretación e intervenciones erróneas en algunas piezas.

Insistimos en una cuestión que creemos de suma importancia, que es que las piezas de artillería de bronce son uno de los elementos más duraderos de un pecio y suelen ser muy utilizadas para identificarlo, y aunque esta observación no corresponde al campo de este trabajo, mantenemos la advertencia sobre el extremo cuidado con que hay que actuar en la arqueología subacuática, al tratar de determinar la nacionalidad de la embarcación por medio de la artillería encontrada en el pecio.

\section{c) Hipótesis referida a que el peso de la pieza es el que va grabado en ella}

Pasamos a intentar descifrar los signos grabados sobre el zuncho que refuerza la caña en la parte en que se acopla el másculo, pues como comenta Morin, algunos fabricantes venecianos solían grabar ahí sus iniciales (Fig. 10).

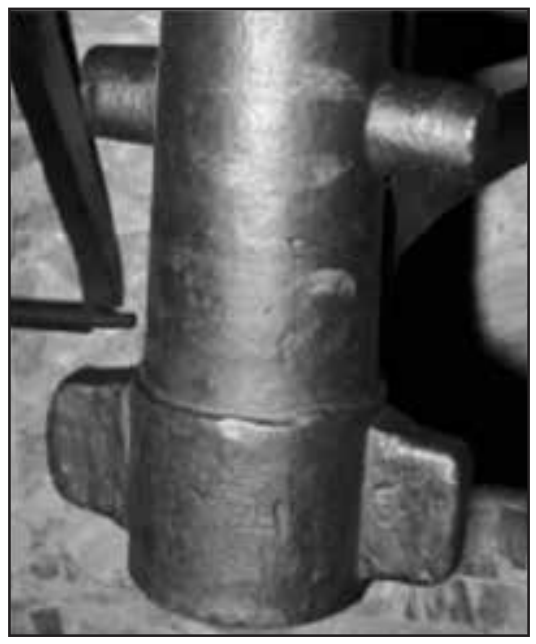

Figura 10. El zuncho de un moschetto da braga con las letras Z U grabadas. Fuente: Morin, 2011.

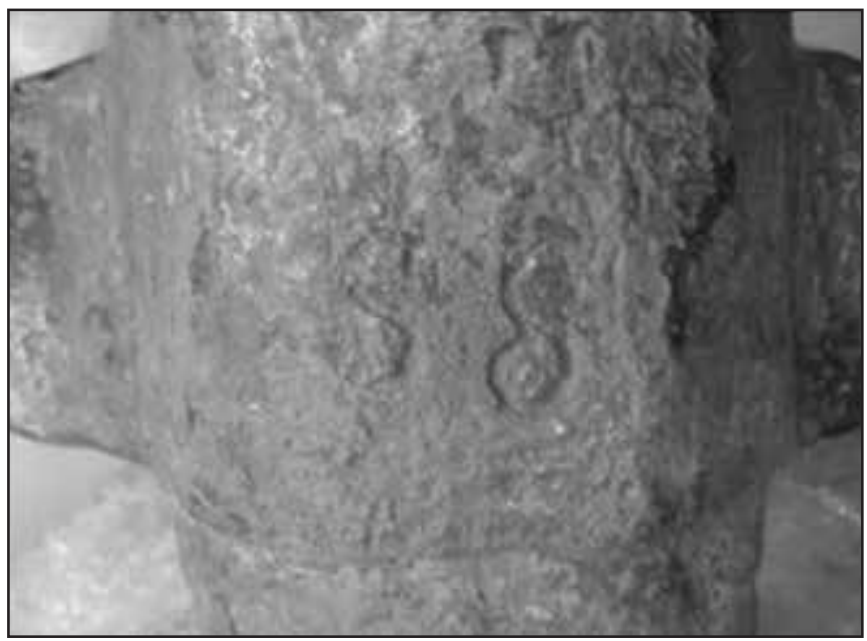

Figura 11. El gran zuncho de refuerzo del final de la caña con las dos "orejas" que servían para trincar la braga. Sobre el zuncho aparece grabado S 8 .

Lo grabado (Fig. 11) nos ofrece tres posibles interpretaciones: la cifra 58; la cifra 85; la letra $\mathrm{S}$ y el símbolo 8 , que podría ser una madeja u otro objeto estilizado. Para las cifras, que parece la opción más lógica suponiendo que represente el peso de la pieza, hemos elaborado la siguiente tabla para traducir a medidas actuales el supuesto peso del esmeril, utilizando todas las posibles opciones:

Tabla 2. Cálculo del peso del esmeril de braga.

\begin{tabular}{|c|c|c|}
\hline Tipo de libra & Cifra 58 & Cifra 85 \\
\hline Sottile 302,025 g. & $17,517 \mathrm{~kg}$. & $25,672 \mathrm{~kg}$. \\
\hline Grossa 477,494 g. & $27,694 \mathrm{~kg}$. & $40,587 \mathrm{~kg}$. \\
\hline
\end{tabular}


El peso que resulta más próximo al de la pieza encontrada es el de $40,587 \mathrm{~kg}$, y es coherente que sea en libras grossas, que eran las que se utilizaban para pesar la artillería (Fig. 12). Ahora bien, la diferencia de este peso con el de la pieza en estudio $(37,8 \mathrm{~kg})$ es de $2,78 \mathrm{~kg}$, lo que viene a ser unas 5,8 libras grossas. Un peso de esas características se media con una romana de mano, con lo que el error de medición no debería de llegar a una libra.

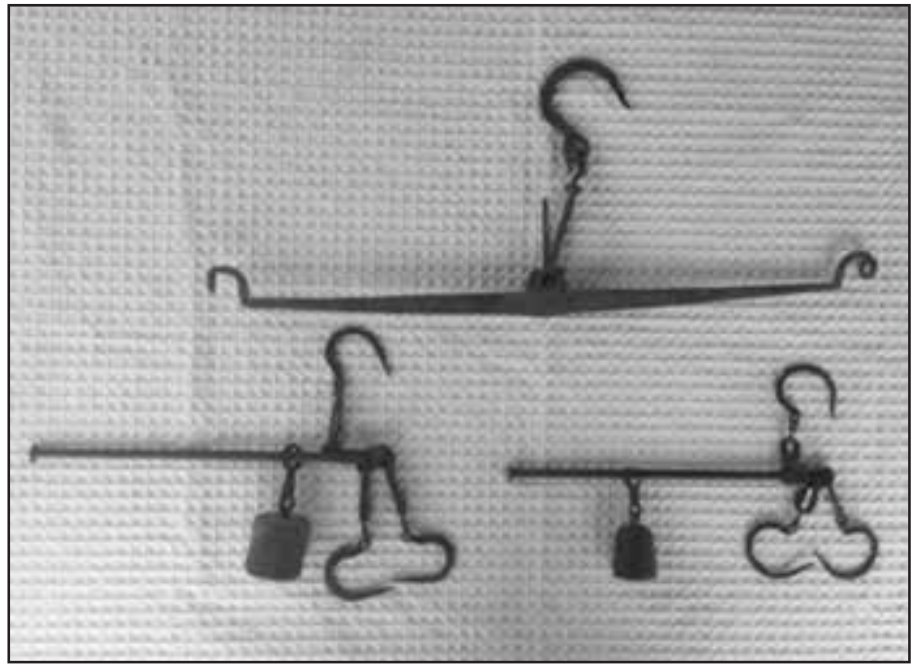

Figura 12. Estatera (faltan los platillos que se colgaban de cada extremo, en uno de los cuales se coloca el peso a medir y en el otro las medidas de peso) y dos romanas del siglo XVIII y XIX. Fuente: Colección P. Fondevila.

Ésta es una forma de interpretar los signos grabados que otros autores consideran que se refiere al peso de la pieza. Vamos a analizar esta forma de medición.
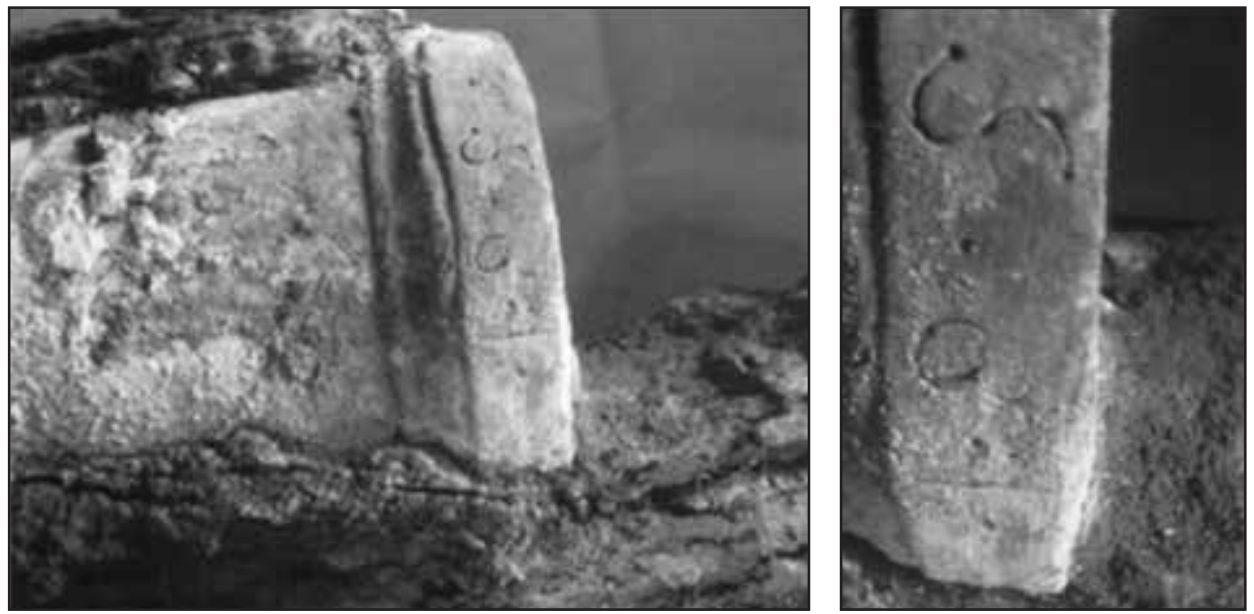

Figura 13. Fotografía de otra pieza veneciana de artillería ligera. Fuente: Scordato, 2011. La marca es parecida a la del moschetto de braga que estamos estudiando (Fig. 10). 
Según el trabajo de Scordato (2011), la autora infiere que la marca que aparece grabada en la pieza que ella analiza (Fig. 13), la cual interpreta como la cifra 185, es la expresión del peso en libras grossas venecianas, que corresponden a $88,25 \mathrm{~kg}$. La pieza que supone que es, un pedrero de braga o pretiere da braga, tendría, según Scordato, un peso de 102,5 kg, el cual considera no muy apartado de los 88,25 kg: "not too far from the 88,25 engraved weight of the barrel" (Scordato, 2011). En esta última frase no compartimos la opinión de la autora citada. Aunque este peso no se puede medir con una romana de mano, cualquiera de las que disponían en las fundiciones, sin tener que llegar al tamaño de la de la figura 4, podría hacerlo perfectamente. Un error de $14,35 \mathrm{~kg}$, que equivalen a 30 libras grossas, es muy grande para un aparato de medición muy sencillo y perfectamente comprobable.

Por otro lado, el grabado del peso en las piezas de bronce, proporcionadas por las distintas naciones a buques mancos y galeras dependientes de ellas, tenía un fin fiscalizador. Cuando se inutilizaba alguna de ellas, había que devolver exactamente el peso de bronce inicial, con objeto de que se enviase a la fundición para formar una nueva pieza. Esta práctica no tenía sentido cuando el que adquiría una pieza era el armador o capitán de una embarcación de comercio. A éstos solamente les interesaba la eficacia de una pieza y que les costase lo menos posible, eliminando adornos que aumentaban el precio de esta; por lo tanto para ellos registrar el peso no era importante.

En cuanto a la posible interpretación del símbolo $\mathbf{S} \mathbf{8}$ no hemos podido encontrar ninguna referencia ni posible explicación. Cabe destacar la similitud de las marcas con las de la figura 13 (que representa la boca de fuego hallada por Scordato). De todas formas éste no es un dato relevante para la identificación de la pieza.

En definitiva, del estudio del origen de la pieza podemos afirmar: 1) que la pieza encontrada, a la que falta, entre otras el másculo de bronce, no lleva ninguna señal de ser una pieza oficial de la Serenísima; 2) las diferencias de las supuestas marcas del peso con la medida de las piezas no parecen aceptables. En el caso del moschetto no puede interpretarse que el peso grabado incluya el de los dos másculos de bronce, pues estos dos pesarían bastante más que los $2,7 \mathrm{~kg}$ de diferencia.

\section{d) Hipótesis sobre la datación de la pieza}

Otro dato nos ayuda a situar este tipo de pieza en la segunda mitad del siglo XVI. Un documento ya mencionado nos proporciona la siguiente información:

Inventario de la galeota nombrada Santiago del Ilustrisimo Marques de Santa Cruz Capitan General de las galeras del Reyno de Napoles por su Magestad y de su...la qual se consina por mandado de su Señoria Ilustrisima a Antonio Scalfatano patron della... Un cannon pedrero de metal de peso quintales - con su caxa nueva de madera guarnecida de hierro de peso ochenta y dos rotolos. Dos esmerilles chiccos de metal con quattro masculos de peso todo dos quintales, con dos codettas, dos forquettas, seys cunnos, y dos cruçes todo de hierro para dichos esmerilles de peso çinquenta y un rotolos. ${ }^{17}$

Aunque el documento no está datado, el personaje citado y el lugar, sitúan la fecha de la descripción de los esmeriles, que coincide con la del moschetto da braga, en torno a 1571/1577. Por otro lado, la posibilidad de que la pieza que estamos analizando formase parte de la carga de la nave veneciana hundida en 1586 y que no se recuperó, ${ }^{18}$ nos aproxima a la fecha de reali-

\footnotetext{
17 Archivo del Marqués de Santa Cruz, Palacio de Santa Cruz, Madrid, caja 74.

18 Archivo General de Simancas, Guerra Antigua, Secc. Mar y Tierra, Leg. 214-62
} 
zación de la misma. De acuerdo a cómo apareció (torsión de la caña), nos inclinamos a pensar que fuera en torno a esas fechas la fabricación de la pieza.

Todo ello nos lleva a inferir que la pieza objeto de este estudio se ajusta en dimensiones, calibre y forma a un esmeril de braga o moschetto da braga veneciano de la segunda mitad del siglo XVI.

\subsection{EstUdio DETALLAdo DE LA PIEZA.}

a) Medicion del calibre.

El primer dato a determinar, una vez tomadas todas las medidas de la pieza, es su calibre. Pero, en los cañones de ánima lisa, el calibre o diámetro del ánima no correspondía, como actualmente sucede con los cañones de ánima rayada, con el diámetro del proyectil. Existía una diferencia entre el díametro del ánima y el de la bala o pelota, denominado viento:

...el dar el viento á la bala es un intervalo entre la bala y el hueco de la pieza, que no entra muy justa y apretada; siendo mal redonda pone en peligro de reventarse la pieza; ni tampoco debe entrar la bala muy floja, porque sería de poco efecto, porque no tomará toda la fuerza de la pólvora y se iría en el viento demasiado, y así se ha de ajustar á que tenga sólo el viento necesario (Fernández Duro, 1996: 491).

Este punto es esencial pues, a no ser que encontremos la pieza cargada y con la bala en muy buen estado de conservación (lo que permitiría obtener su peso y diámetro con seguridad), para determinar el calibre de su bala habrá que medir el diámetro del ánima, y a este

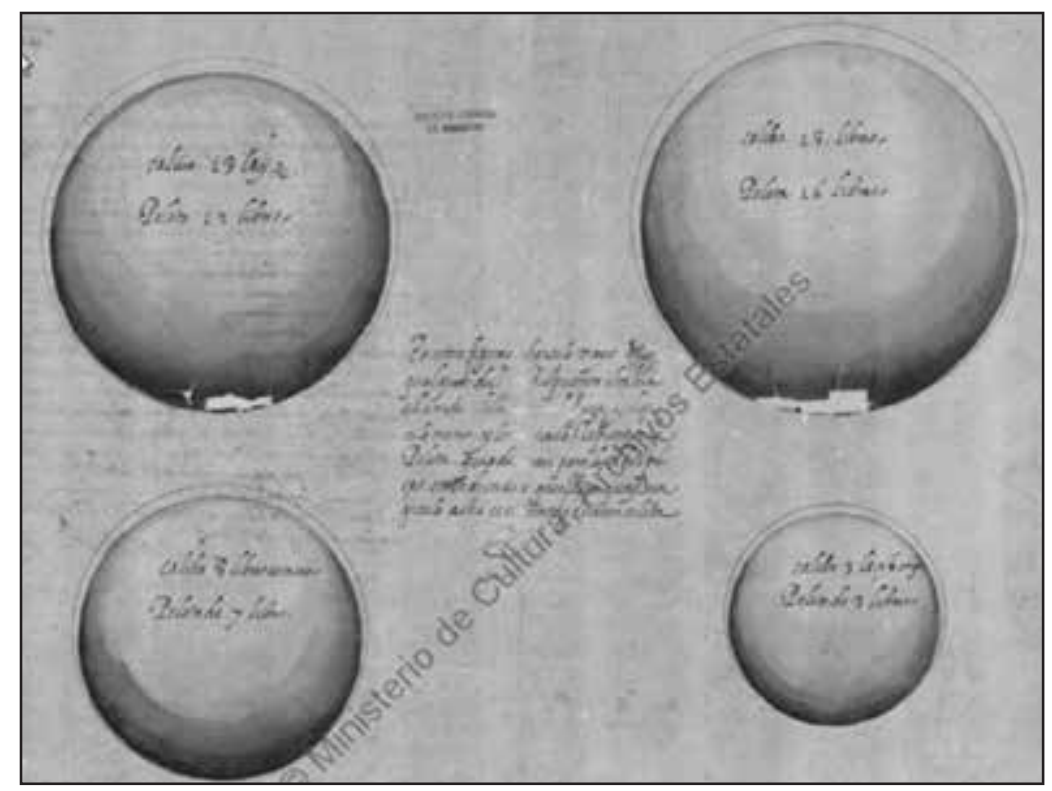

Figura 14. Distintos calibos y pelotas. El viento se expresa, en el dibujo, por la diferencia entre el diámetro del ánima de la pieza y el diámetro de la pelota. Otra forma que aparece para establecer el viento adecuado, es indicar el peso de la bala y el que tendría una bala del diámetro del ánima o calibo. Fuente: Archivo General de Simancas. MPD, 05, 020. 
valor quitarle el viento para obtener el diámetro de la misma. Una vez hallado hay que transformar en peso según el caso, y considerar el material del proyectil, (hierro, plomo o piedra), para determinar su calibre, que en esa época se ajustaba según el peso de la bala, e iba expresado en libras u onzas castellanas en España (Fig. 14).

Traer a colación todas las distintas reglas que se proponen en los libros y manuscritos de la época no tendría objeto, por aportar cada autor reglas diferentes, que si bien próximas, proporcionarían, sobre todo en los calibres pequeños, que es el caso de este trabajo, resultados distintos e inseguros. Por tanto, emplearemos como referencia los valores del viento que se utilizaban en las galeras españolas en la época estimada de datación de la pieza analizada, segunda mitad del siglo XVI, extraídas de relaciones de artillería de galeras, las cuales consideramos comunes a las marinas mediterráneas de ese momento. El siguiente documento nos proporciona los vientos de los esmeriles de las galeras españolas:

Relacion de las piezas de Artilleria que ay en todas las galeras de España y de su peso y Calibo que tienen en el Puerto de Santa Maria en 11 de noviembre de 1590. Galera Capitana: Quatro esmeriles el uno pesa tres quintales y cincuenta libras peso de Castilla, tira de vala una libra de calibo libra y media; el otro fundición de Napoles pesa dos quintales y medio tira de vala ocho onzas tiene de calibo doze; otro pesa quintal y medio tira de vala ocho onzas y doze de calibo; otro del propio peso y calibo. ${ }^{19}$

\section{b) Fábrica de la bala o pelota de un esmeril}

La bala o pelota de esmeril era un proyectil de pequeño calibre, fabricado con plomo, del que se tenía noticia de que llevaba algún dado o cubo de hierro en su interior, sin mayores precisiones. Esta indeterminación impedía calcular la densidad de la pelota, al estar formada por dos diferentes metales y no conocer su proporción. De esta forma no se podía calcular el diámetro de la esfera, formada por la pelota, en función de su peso.

Afortunadamente, hemos localizado un documento que nos proporciona todos los datos para hacer el cálculo citado: «5 formas (moldes) de bronce para bala de esmeril; 274 balas de esmeril de plomo. Pesa cada una una libra. Los dos tercios son de plomo y el otro tercio de hierro; 450 dados de hierro de balas de esmeril pesa cuatro onzas el uno». ${ }^{20}$

Teniendo en cuenta que las cifras están en medidas de Nápoles y que la libra era de 12 onzas, se confirma doblemente que la proporción de plomo/hierro era $2 / 1$. Con estos datos se obtiene una densidad de la pelota de 10,015. Haciendo el cálculo para el esmeril o moschetto da braga, y utilizando los dos tipos de libras venecianas: de peso sottile, equivalente a 302,025 g y de peso grosso, que valía 477,494 g (Guglielmotti, 1889) y el que proporciona Morin para el peso sottile, 301,2, resultan los siguientes "vientos" de las balas:

Tabla 3. Estimación de los vientos de las balas.

\begin{tabular}{|l|c|c|}
\hline Tipo libra & Calibre ánima $47 \mathrm{~mm}$. & Calibre ánima $48 \mathrm{~mm}$. \\
\hline Sottile $302,025 \mathrm{~g}$. & Viento $8,38 \mathrm{~mm}$. & Viento $9,38 \mathrm{~mm}$. \\
\hline Sottile según Morin $301,2 \mathrm{~g}$. & Viento $8,42 \mathrm{~mm}$. & Viento $9,42 \mathrm{~mm}$. \\
\hline Grossa 477,494 g. & $* * *$ & $* * *$ \\
\hline
\end{tabular}

*** El diámetro de la pelota resulta mayor que el diámetro del calibo o calibre del ánima.

19 Archivo Museo Naval de Madrid, Colección Sanz de Barutell, art. 4º núm. 1070.

20 Biblioteca Nacional de España. Mss 010433. Nápoles 5 de diciembre de 1577. Cuenta y liquidación, por los oficiales del Rey, de los menoscabos que tuvieron las quarenta galeras que el Marqués de St ${ }^{a}$ Cruz tuvo de SM por asiento los años 1575 y 1576. 
A la vista de los vientos obtenidos, es evidente que la pelota de plomo tenía que ser de una libra sottile. Estos resultados coinciden con lo indicado por Morin, el cual sostiene que las balas de plomo venecianas se medían en libras sottili:

Fino ai pezzi da 12 libbre compresi, la designazione del calibro era data dal peso della palla di biombo che veniva sparata nella prova forzata del pezzo stesso: un sacro, ad esempio, venia assoggettato alla prova con palle di biombo del peso di 12 libbre sottili alla veneziana (1 libra $=301,2 \mathrm{~g}$ ) (Morin, 2011).

Por otro lado, los datos de calibre $(47 \mathrm{~mm})$, longitud $(84,5 \mathrm{~cm})$, peso de la bala (1 libra sottile) y forma, coinciden con los indicados por Morin: «Tra i pezzi a retrocarica trovamo. - il moschetto da braga da 1 libbra, con un calibo di circa $45 \mathrm{~mm}$ e lungo intorno al metro» (Morin, 2009: 21).

\subsection{Descripción de Las Partes, EMPLeO y MANeJo De La Pieza.}

Como ya hemos manifestado este esmeril es del tipo de braga, es decir, con la recámara completamente abierta. Es, por tanto, una pieza de retrocarga tal como se entendía en la época, en el cual el concepto de retrocarga solamente abarcaba la carga de pólvora, mientras que la bala o pelota se cargaba, con su correspondiente taco, por la boca.

Como ya hemos señalado anteriormente, la carga de pólvora estaba almacenada en un recipiente cilíndrico de bronce llamado másculo (también conocido como recámara, cámara, servidor o alcuza). Éste se cargaba en sus 3/5 partes de pólvora, dejando un espacio de aire y cerrándolo con un taco de madera blanda. En su parte posterior, relativamente gruesa, tenía labrada una canal donde entraba la cuña, calce o cunno, de hierro, el cual, pasando a través de los dos orificios de la braga, atochaba el másculo contra la parte trasera del ánima, al mismo tiempo que impedía el giro de aquel, dejando el fogón, focóne o lumiera, en posición vertical. Para manejar el másculo disponía éste de una gruesa asa de bronce que, cuando aquel estaba trincado a la pieza, quedaba girada a la derecha unos $30^{\circ} / 40^{\circ}$, de forma que no molestase a la puntería ni estorbase el uso del botafuego, al mismo tiempo que servía para recibir los golpes de la maceta de madera, utilizada para desencajar el másculo de la caña de la pieza después del disparo, de ahí su grosor. La bala o pelota se introducía por la boca de la pieza y a continuación el taco, haz de filásticas que sirve para mantener la bala fija, apoyada contra el taco de madera que cerraba la boca del másculo. Para introducir la pelota y el taco se utilizaba el atacador o refilador, asta de madera con un zoquete del mismo material en su extremo.

Sin embargo, estas piezas pequeñas, como ya se demostró con el hallazgo y estudio de un esmeril de la segunda mitad del siglo XVI (Fondevila y Sánchez-Baena, 2012), utilizaban una vara de madera dura, de longitud cercana a la del ánima, acabada en un ensanchamiento, que servía, además de atacador, de tapaboca de la pieza.

Una vez cargada el arma, se apuntaba por medio de la codetta o rabiza. Para hacer fuego, es decir, disparar, se aplicaba el botafuego o botafogo al fogón del másculo. El botafuego consistía en una pequeña asta de madera que, por un extremo, acababa en un pincho de hierro para clavarla en la cubierta, y por el otro tenía una raja o hendidura, donde se metía a presión la cuerdamecha encendida (Fig. 15).

Las balas de plomo que disparaba el esmeril de braga se fundían a bordo de las embarcaciones, para lo cual disponían estas de cucharas o crisoles para fundir el plomo y de moldes para fabricar las balas. También podía disparar pelotas de hierro, pero estas tenían el inconveniente de la provisión, ya que no se podían hacer a bordo y, sobre todo, de su menor energía 


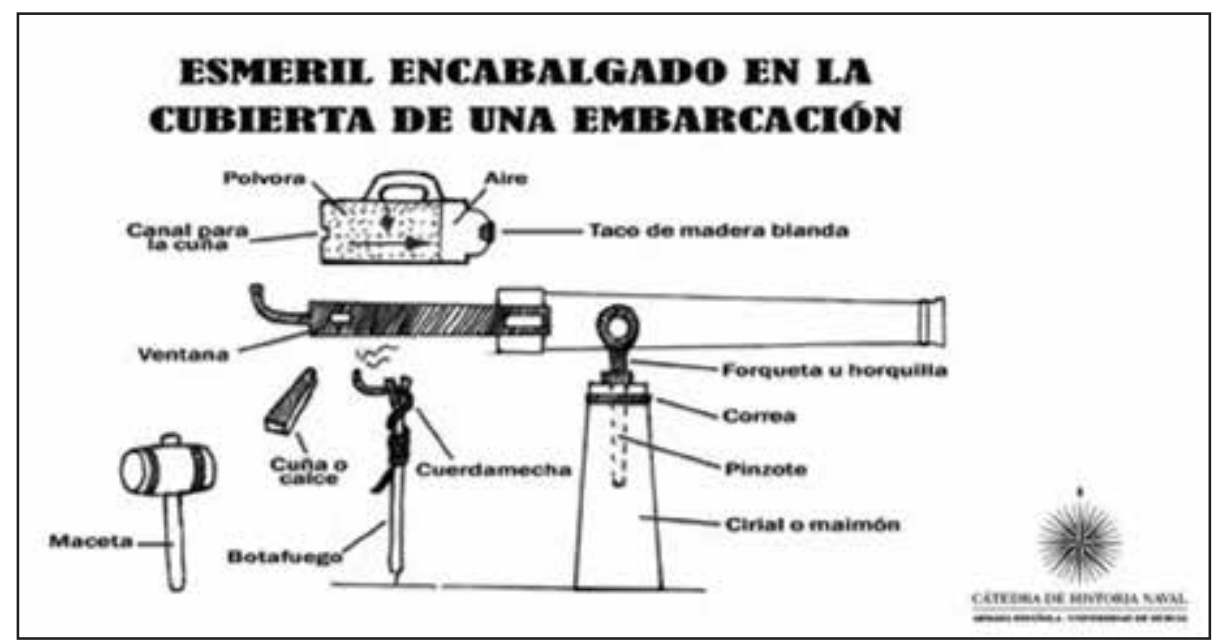

Figura 15. Esmeril encabalgado en la cubierta de un buque.

cinética, casi la mitad que las de plomo. Para evitar la perdida de energía por aplastamiento de la bala de plomo contra un objeto sólido, se echaba un dado, pequeño cubo o hexaedro de hierro, en el interior del molde cuando se vertía en este el plomo fundido, dados que también se empleaban como metralla para rellenar las lanternas, cilindros huecos de madera blanda que hacían la función de botes de metralla (Fig. 16):

Nápoles, 8 de mayo de 1587. Inventario de las municiones, artillería, armas y otras cosas, consignada a Federico Giudice, patrón de la galeaza capitana asi para el servicio de la dicha galeaza como para llevar de respeto a España:

- Cinco cucharas de hierro para derretir plomo, las dos grandes y tres pequeñas, de peso de 9 rótulos.

- Quatro moldes de bronze con sus mangos de hierro para hazer balas de esmeriles.

- Un quintal de dados de hierro para las lanternas y para hazer balas de esmeriles. ${ }^{21}$

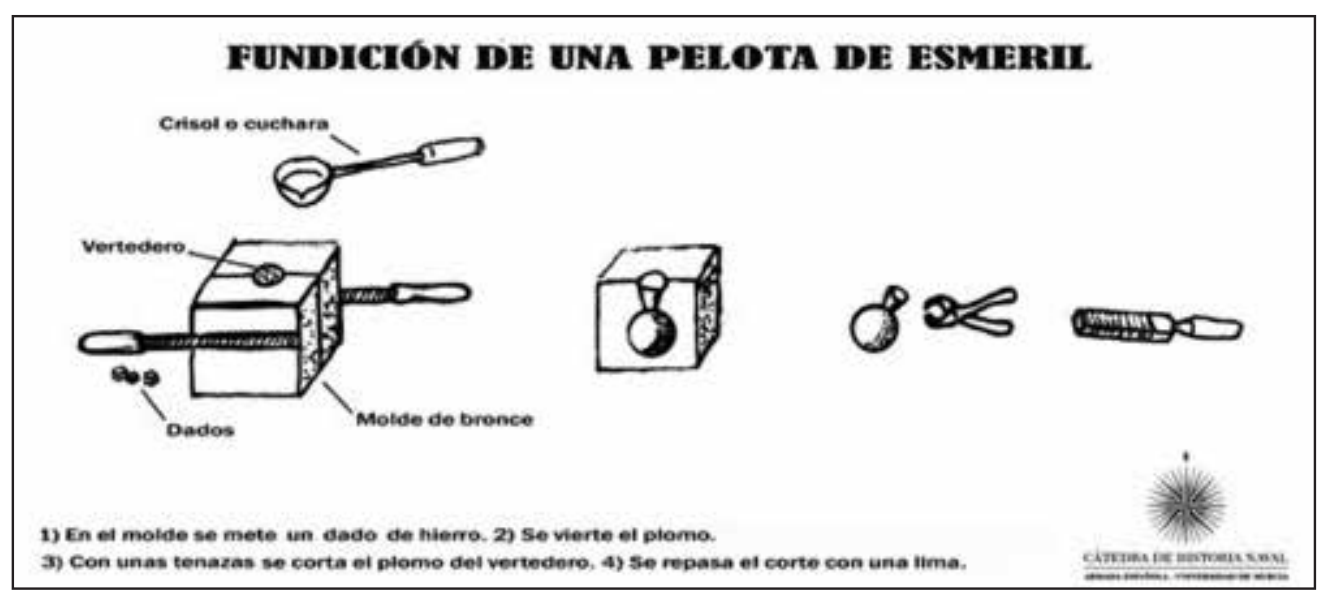

Figura 16. Explicación gráfica sobre cómo se funde la pelota de un esmeril.

21 Archivo General de Simancas, Guerra Antigua, Secc. Mar y Tierra, Leg. 214-46. 
Por último, recordar que el esmeril de braga, como los otros tipos de esmeriles, era un arma "antidotación", mientras que los cañones de crujía, sacres y moyanas, eran piezas "antibuque", que servían para tirar contra blancos determinados (tirar a puntería), pues para tirar al conjunto de la dotación enemiga se empleaban las descargas de arcabucería y los pedreros; aunque esta división de funciones no era rígida, pues, en ocasiones, las piezas "antibuque" se utilizaban contra la gente enemiga cargándolas con cadenas, hierros viejos y lanternas.

\section{CONCLUSIÓN}

La pieza de bronce hallada en la Torre del Oro es un esmeril de braga con una pequeña deformación y algunas pérdidas de material en las orejas, muñones y en el brocal o joya. Pesa $37,8 \mathrm{~kg}$ y mide $84,5 \mathrm{~cm}$ y tiene un calibre de $47 \mathrm{~mm}$. La pelota de esta pieza sería de plomo con alma de hierro y pesaría una libra sottile veneciana. Por lo tanto, es un arma de pequeño calibre y por ello destinada a blancos humanos ("antidotación"), no a embarcaciones ("antibuque"). No ha sido posible descifrar con seguridad las marcas de la caña, aunque éstas no son relevantes para la identificación de la pieza.

Sus características técnicas, especialmente el calibre, la hacen claramente identificable como una pieza de la segunda mitad del siglo XVI, probablemente de origen veneciano, denominado moschetto da braga en italiano. El arma no está completa, ya que sólo ha aparecido la caña o cañón de bronce, pero no el resto de piezas que facilitan su uso (la braga de hierro que le da nombre, la horquilla y el másculo), lo que, unido a sus depósitos calcáreos, hace inferir que estuvo sumergida durante mucho tiempo en el mar y que cuando emergió es muy posible que fuera por casualidad, enredada en alguna red.

Se ha hallado la forma de fundir las pelotas de plomo y hierro de los esmeriles, hasta ahora, que sepamos, desconocida, y con ello la densidad del proyectil. Este conocimiento nos permite, sabido el peso de la pelota (dato muy corriente en los documentos, pues las piezas se definían por el peso en libras u onzas de su bala), determinar el calibo o calibre del arma, cualquiera que sea la nación mediterránea que la fabricó.

$\mathrm{Su}$ origen veneciano no significa, ni mucho menos que durante su vida útil viajara siempre en una galera o galeón de esa República, sino que por apresamiento, desarme, trueque o compra pudo ser utilizada por embarcaciones de cualquier otra nacionalidad, tanto cristianas como musulmanas.

\section{FUENTES}

Aguilar, M. C. (1640-1641): Advertencias a Navegantes. Códice 13390. Biblioteca Nacional de Portugal. Álava y Beamont, D. de. (1590): El perfecto capitan instruido a la disciplina militar y nueva ciencia de la Artillería. Madrid, Pedro Madrigal.

Alberguetti, S. (1699): Nuova artigleria veneta. Venecia.

Arantegui y Sanz, J. (1891): Apuntes históricos sobre la Artillería Española en la primera mitad del siglo XVI. Madrid, Imprenta del Cuerpo de Artillería.

Capo Bianco, A. (1598): Corona e palma militare di artigleria. Venice.

Collado de Lebrija, L. (1592): Plática manual de artillería. Milán, Pablo Gotardo Poncio.

Escalante de Mendoza, J. (1575): Itinerario de Navegación. Madrid, Museo Naval Madrid. Edición fácsimil de 1995.

Firrufino, J. C. (1626): Platica manual y breve compendio de artillería. Madrid, Viuda de Alonso Martín.

García de Palacio, D. de (1587): Instrucion Nauthica, para el buen uso, y regimiento de las Naos, su traça y govierno conforme a la altura de Mexico. México, Pedro Ocharte.

Guglielmotti, A. (1889): Vocabulario Marino e Militare. Roma, Voghera Carlo. 
Ríos, V. de los (1767): Discurso sobre los Ilustres Autores e Inventores de Artilleria. Madrid, Joachin Ibarra.

Rojas, C. (1598): Teoria y practica de fortificacion, conforme las medidas y defensas de los tiempos, repartida en tres partes, por el capitan Christoval de Rojas, Ingeniero del Rey nuestro Señor Don Felipe III. Madrid, por Luis Sanchez.

Salas, R. de (1831): Memorial Historico de la Artilleria Española. Madrid, Sucesores de García.

Ufano, D. (1613): Tratado de la Artilleria y uso della Platicado por el capitan diego ufano en las guerras de Flandes. Bruselas, Juan Monarte.

\section{BIBLIOGRAFÍA}

Ashtor, E. (1981): «L'artiglierie Veneziana e il commercio di Levante», Armi e cultura nel Bresciano (1420-1870). Brescia, Ateneo de Brescia: 141-154.

Avery, V. J. (2003): «State and Private Bronze Foundries in Cinquecento Venice: New Light on the Alberguetti and di Conti Workshops», P. Motture (ed.), Large Bronzes in the Rennissance. Washington, National Gallery of Art: 241-275.

Boudriot, J. (1992): L'Artillerie de Mer. París, ANCRE.

Fernández Duro, C. (1996): Disquisiciones náuticas. Vols. I y VI. Madrid, Ministerio de Defensa.

Fondevila Silva, P. (2010): «Tipología de las galeras españolas del siglo XVI». Revista de Historia Naval, 110: 25-52.

Fondevila Silva, P. y Sánchez Baena, J. J. (2012): «Una nueva pieza de artillería de galeras del siglo XVI: El esmeril bastardo "Matacapitanes"». Gladius, XXXII: 185-210. https://doi.org/10.3989/ gladius.2012.0009

Guilmartin, J. F. (2002): Gunpowder and Galley. Changing technology and Mediterranean Warfare at sea in the sixteenth century. Londres, Cassell \& Co.

Morin, M. (2002): La battaglia di Lepanto: alcuni aspetti della tecnologia navale Veneziana. Versione aggiornatta della relazione presentata al convengo Mediterraneo sull'evento di Lepanto. Odierne interpretación e memorie. Istituto di Studi Militari Marittimi, Venezia, 8 Novembre. Fuente: http:// www.storiadivenezia.net/sito/saggi/morin_lepanto.pdf [Consulta 23-07-2016].

Morin, M. (2009): «Alcune note sui Fonditori veneziane d'artiglierie nel XVI secolo e sulle loro opere». Quaderni di Oplologia, 28 (1): 3-36. Fuente: http://www.arsang.org/Z-Frames\%20STORICHE/Alcune $\% 20$ note\%20sui\%20Fonditori\%20veneziani.pdf [Consulta 23-07-2016].

Morin, M. (2011): «Artiglierie in ámbito veneziano: tipología e techniche di realizzacione». Bolletino d'Archivo dell 'ofccio storico della Marina Militare. Fuente: http://www.marina.difesa.it/documentazione/editoria/bollettino/Documents/2011/dicembre/santarini.pdf [Consulta 23-03-2016].

Ridella, R. G., Galili, E., Cvikel, D. y Rosen, B. (2016): «A late 16th to early 17th century European shipwreck carrying. Venetian ordnance discovered off the Carmel coast, Israel». International Journal of Nautical Archaeology, 45 (1): 180-191. https://doi.org/10.1111/1095-9270.12173

Santarini, M. (2011). «La artiglierie della Marina Veneta nel XVI secolo». Bolletino d'Archivio dell'Ufficio Storico della Marina Militare. Roma. Suplemento dic. 2011: VI. Fuente: http://www. marina.difesa.it/documentazione/editoria/bollettino/Documents/2011/dicembre/santarini.pdf [Consulta 23-03-2016].

Scordato, R. (2011): «Two Venetian swivel guns from Messina Strait, Sicily». In: Beltrame, C., \& Ridella, R. G. (2011): Ships and Guns: The Sea Ordnance in Venice and in Europe Between the 15th and the 17th Centuries. Oxbow Books: 28-34.

Vicente Maroto, M. I. (2002-2003): «Las escuelas de artillería en los siglos XVI y XVII». Quaderns d'historia de l'enginyeria, V: 1-12. http:/upcommons.upc.edu/bitstream/handle/2099/734/escuelas_artilleria.pdf? sequence $=1$ [Consulta 23-01-2017].

Vigón, J. (1947): Historia de la Artillería española. Madrid: CSIC.

Recibido: 16-05-2016

Aceptado: 21-10-2016 